\title{
Maximizing Indigenous Student Learning In The Mainstream With Language And Culture
}

John W. Schwieter, Wilfrid Laurier University, Canada

J. Luis Jaimes-Domínguez, Wilfrid Laurier University, Canada

\begin{abstract}
In this paper, we explore the importance of being conscious of the needs of indigenous students within the education system in order to increase their learning process and decrease their dropout rates. Specifically, we discuss how Mayan language, culture, and ideologies affect the educational outcome of Mayan students in mainstream classes in Guatemalan schools. From this discussion, we highlight the impact that these factors have on both teacher training and the education of the indigenous student population. A simple "teaching to learn - learning to teach" model is explained which discusses the importance of multilingual and multicultural aspects of teacher training and real-life implications in the indigenous student learning process.
\end{abstract}

Keywords: language and culture, minority education, indigenous teaching and learning.

\section{INTRODUCTION}

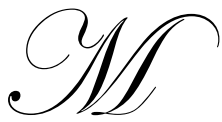

aximizing the learning process is one of the many goals of a teacher. Among many things, a teacher has the difficult task of ensuring that he/she is accommodating the needs of all studentsincluding minority students who may hold linguistic and/or cultural values that differ from the mainstream. However, this may be cumbersome for a teacher who lacks knowledge and understanding of the minority's language and culture or when other external factors, such as poverty and low national literacy rates, are predominant.

In the upcoming sections, we first introduce a general outline of how indigenous students-particularly Mayans - form part of the education system in Guatemala. Also within the first section, we discuss the marked gap in academic achievement between indigenous and non-indigenous students and the reasons that have been put forth explaining such differences. Following this, we then turn to how Mayan traditions-linguistic and cultural-and ideologies contribute to how these students fare in academia. Finally, based on previous research and the impact that Mayan traditions have on their children as students, we conclude this paper by outlining some critical issues that teachers must be conscious of in order to increase academic achievement among indigenous students.

\section{INDIGENOUS STUDENTS IN MAINSTREAM CLASSES: THE MAYAN CASE}

\section{Mayans As A Minority (And Majority) Student Population}

There are many indigenous students scattered out throughout parts of the world. In Latin America alone, some of the countries with the highest indigenous populations include Guatemala, Bolivia, Mexico, Chile, Ecuador, and Peru. Guatemala, like the latter mentioned countries, is a linguistically and culturally diverse country. This can clearly be observed in the new Constitution of the Republic of Guatemala which "officially recognized the multilingual, pluricultural nature of the society and the rights of its peoples to their "cultural identity with their values, their language, and their customs' (Article 58)" (Richards \& Richards, 1997, p. 189). This is an important element within Guatemala given that it is estimated that $43 \%$ of the 14.2 million inhabitants are indigenous 
(Embassy of Guatemala, 2007). Among this indigenous population, there are 23 languages, 21 of which are Mayan. This rich linguistic and cultural diversity provides multiple challenges to teachers who seek to be conscious of indigenous students' needs. Although one of the desired outcomes of the education process in Guatemala is not only a bilingual society, but an intercultural one as well (Hornberger, 2000), teachers often times must create many of their materials if they want them to be culturally relevant. They also face the challenge of involving parents and community members in meaningful ways in order to underscore their role in language and culture maintenance (Delany-Barmann \& Schwieter, 2004).

The indigenous student population creates an intricate role in the school system. History and research have shown that it is more likely that ethnic minority groups suffer from lower academic achievement (Derwing, DeCorby, \& Ichikawa, 1999; Foley, 1991; Hall \& Patrinos, 2006; Schwieter, 2002; Schwieter, submitted). Ironically, however, in countries where the indigenous inhabitants make up nearly the majority of the population, statistics have mirrored what has been revealed in communities in which they are the minority-they are academically staggering significantly behind their non-indigenous counterparts. Overall, indigenous students begin their schooling with more disadvantaged backgrounds, study in schools with fewer resources, and perform worse on exams. Studies have shown that indigenous students performed significantly worse than non-indigenous students on both Spanish and math exams (Hernández-Zavala et al., 2006). When exploring the reasoning behind this large gap, Hernández-Zavala et al. have revealed a number of factors that underpin low academic achievement among indigenous students. They have suggested that,

Indigenous students consistently have fewer reading materials at home, less access to electricity, and parents with less education. Compared to teachers of non-indigenous students, teachers of indigenous students tend to be more often male, less experienced, and less educated. The schools of indigenous students more often lack Spanish and math textbooks and have conditions that students describe as bad (p. 14-15).

In addition to these factors, indigenous students are more likely to attend multigrade classes in which there are students with varying grade levels, ages, and abilities (Anderson, 2003). In sum, when indigenous students begin school, they begin with backgrounds likely to undermine their learning. When coupled with the lacking facilities and human resources of indigenous schools, this may reinforce the early disadvantage that indigenous students have in the education system.

McEwan and Trowbridge (2007) explain the educational achievement gap similarly to Hernández-Zavala et al. (2006) by arguing that the complicated issue of lower academic attainment among indigenous students appears to be three-fold. First of all, they suggest that indigenous parents have less schooling and lower incomes, which are two indicators of the quality of the educational environment in the home. The second reason posits that indigenous students normally attend schools with fewer instructional materials, lower-quality buildings, and less-qualified teachers. Finally, McEwan and Trowbridge argue that the third cause of low academic achievement among indigenous students revolves around the fact that schools rarely address linguistic diversity among indigenous children. This creates linguistic barriers that may be unbreakable to those whose dominant language is not the language of instruction (i.e., Spanish). Although less can be done regarding McEwan and Trowbridge's first reason, steps can be taken that attempt to reduce the negative effects the second and third reasons have on indigenous students and their learning.

With regard to the quality of school, there is evidence that suggests that indigenous children attend primary schools of lower quality. Many factors could be attributed to this, for example as mentioned above, HernándezZavala et al. (2006) have shown that indigenous children are less likely to have access to text books and their teachers, on average, have significantly less teaching experience than those of non-indigenous students. In particular, many teachers who work in areas with large indigenous populations possess limited skills in the regional indigenous language. Although many of these educators may speak the local language, most have no reading or writing literacy. The latter limits the amount and quality of education that teachers can provide Mayan children in their own home languages. Given that nearly $40 \%$ of children in Guatemala start school without a productive knowledge of Spanish, this is quite alarming. 
Previous studies have explored the academic achievement of students by comparing schools with bilingual education programs to monolingual schools (Patrinos \& Velez, 1996; Rubio, 2004). The general consensus in these studies has suggested that students in bilingual education programs score slightly higher than students in monolingual programs. Because of this, a growing number of bilingual programs have expanded across Guatemala. Since 1984, the Programa Nacional Educación Bilingüe Intercultural (PRONEBI) has provided national support for bilingual programs. Later, the Ministry of Education in Guatemala established the Dirección General de Educación Bilingüe Intercultural (DIGEBI) in 1995 which provided such programs further assistance and support. Most recently, the commitment to educational reform was underscored by a project begun in 1999 by the US Agency for International Development (USAID) in cooperation with the Guatemalan Ministry of Education. Since the creation of the latter project, many efforts have been put into El Quiche region (known as El Quiche Department in Guatemala) to increase bilingual/intercultural education. El Quiche region is a particularly excellent place to pilot such a program as it boasts the largest indigenous population in Guatemala with $95 \%$ of its inhabitants being of indigenous origin.

Although bilingual education programs exist within Guatemala, they are far from being universal and, as expected, are much more apparent in rural communities. According to the Encuesta de Condiciones de Vida (ENCOVI) (2000), only 18.3\% of indigenous students receive instruction in both Spanish and a Mayan language within urban communities. Not surprising, this percentage is larger for rural communities which consist of higher indigenous populations where $36.7 \%$ of Mayan children receive instruction in Spanish and a Mayan language.

\section{The Shaping Of Mayan Students}

Essentially, because Mayan students come from a home environment that is culturally, linguistically, and ideologically distinct from that of non-indigenous students, an important consideration to make is how these factors affect their performance as students. We now turn to how Mayan language, culture and ideologies shape the educational experiences of Mayan students in mainstream classes.

Guatemalan law specifies that all students must attend school at least until they complete the third grade. Thus, after a very limited number of years in school, Mayan children many times are no longer able to attend school, returning to their Mayan lifestyle. Unfortunately, this is due to the cost of maintaining a child in a secondary school away from home. Although the cost of attending school is free, there are other expenses that accompany it (e.g., textbooks, school supplies, etc.). As such, finances, in addition to traditional values, play a large role in whether or not Mayan students are able to continue their schooling. With regard to their houses and home life, many Mayan students come from homes where there are no electrical, mechanical, or other facilities. Many times, there may be a general, public telephone in the town's courthouse that can be used only for transmitting administrative messages. Most of the Mayan homes are made of adobe, cane stalks, or less common, stone blocks. Normally, the homes have only one room, a door, and rarely have windows. The roof of their houses are made either from thatch, tile or, in a few cases, sheets of metal. Hard-pack dirt floors are predominant in Mayan homes.

Because of the continuous low literacy rates among Mayans over generations, when a Mayan child is old enough to attend school, it is more likely that he/she will not want to go because this is not a promoted within their culture. Traditionally, Mayan parents, when compared to non-indigenous parents, tend to send their children to school much less frequently. In addition, for most Mayan families, having another child is a way to receive extra income because parents are able to introduce their children to work at a very young age in order to start preparing them to a future adult life.

For centuries, Mayan communities based the education of children at home. It was the parents who taught their children the main activities that girls and boys were to develop to become adults. In many communities, even today, sending children to school is more of an obligation than an opportunity. Some Mayan parents think that, in many cases, sending their children to school would make them lazy and that they would deny executing laborious activities in the future. In fact, Mayan parents may ask themselves, "is going to school for more than a few years going to help my child be a better corn grinder?" Indeed, because instructional materials such as texts are scarce, much of the instruction consists of learning from rote lists of objects and definitions unrelated to theses important aspects of Mayan life. Because of this, the idea of attending school is not something that forms part of traditional 
Mayan life. On the contrary, schools may be seen as a way of escaping the hardships of work within Mayan lifestyle.

As mentioned above, an overwhelming number of Mayan students begin school by facing a language barrier. This issue is augmented for children who come from rural areas in which their contact with the Spanish language is little to none. Mayan students in this scenario must initiate their schooling with a great disadvantage and make substantially less development than their non-indigenous peers. Linguistically speaking, the fact that their home life has not allowed them to achieve higher academic standards is worsened when considering that most teachers of indigenous students do not have sufficient knowledge of the regional Mayan language or culture, limiting their capability to freely entertain the inherent necessities of indigenous students.

In terms of the gender differences between Mayan children, girls are more likely to follow in the steps of their mothers and grandmothers. This entails staying at home cooking, cleaning, and taking care of their children - a tradition that is passed on from generation to generation. Interestingly, Mayan girls more rapidly lose their knowledge of Spanish that they have learned in school because they have less of an opportunity to use it and are ridiculed by other women of the town if they try. In some way, when girls speak Spanish within smaller Mayan communities, it appears as though they are turning their backs on their Mayan heritage.

Mayan boys, on the other hand, will take on jobs that their fathers have done for years, often times forgetting about the "useless knowledge" that school has given them. Only in a small number of cases, boys maintain their Spanish when working in commercial activities within their communities. Even less often, a Mayan family may send their son to a larger school where the boy can complete six grades and possibly become a school teacher. This is far less common, however, for Mayan girls.

\section{LINGUISTIC AND CULTURAL IMPLICATIONS IN THE CLASSROOM}

\section{Language Issues}

Like all indigenous students, Mayan students bring a rich background of linguistic and cultural traditions to the classroom. Teachers must put forth every effort to try to incorporate these issues into their lessons and the curriculum as a whole. The fact that $40 \%$ of Mayan students in Guatemala attend their first day of school with little to no Spanish language abilities is alarming - especially for those who are not fortunate enough to attend bilingual education programs. This could lead to feelings of frustration and intimidation among Mayan students. Indeed, in Schwieter's (2002) study, students with limited language abilities in mainstream classes reported feelings of aggravation and pressure to participate in class because they felt that they were not able to contribute to class discussions. Basically, then, indigenous students in Guatemala with limited to no language abilities in Spanish suffer a loss of content material that is essential to engaging themselves and integrating into the learning environment. Schwieter (2002) discusses the distinction between "living" and merely "surviving" within academia. Living in the school system implies that students are able to understand and engage themselves in their own learning. This, then, leads to the development of knowledge which is incorporated with the pride of knowing that the student has actually "learned something." However, when indigenous students are only able to survive in the education system, they are guaranteed to suffer a great loss of understanding because they lack the linguistic abilities that are necessary for learning development to occur.

An important part of bilingual education is the availability to bilingual reading materials within the school and/or library. This not only shows indigenous students that there is a genuine interest and respect given toward their native language, but also allows them to be able to relate better to the material. Many times because of financial and budgeting issues, this can be a difficult challenge for parents and school administrators. However, every effort should be made to provide as many native language materials as possible to indigenous students.

\section{Cultural Issues}

Another important consideration to make with regard to the education of indigenous students involves cultural issues. As mentioned above, indigenous students have been taught traditional values from their families and 
indigenous community that are culturally distinct from the mainstream. Clearly, if the school is not set up to be an agent for diverse education, students from minority cultures will not receive an education to which they can culturally connect. Furthermore, if attention is not paid to the presence of indigenous cultures, students may feel that these factors are not as important as the cultural values of the mainstream. Indeed, in Schwieter's (2002) study, minority students were bothered when there was not enough cultural recognition given to their native traditions and values. In fact, one participant reported that the only thing she liked about her literature class was that the teacher allowed her (once) to give a presentation on a bilingual book that emphasized the students' minority culture. In this instance, she felt that her culture was valued in the classroom. To this participant's dismay, however, it was not a book that the teacher recommended to the other students in the class.

Another cultural factor that may be beneficial to indigenous students is the recognition of native celebrations. When attention is given to indigenous holidays or special events, students feel as though their culture is "alive" and valued. This facilitates the preservation of indigenous heritage and brings customs to the classroom so that all students can understand its importance and celebrate its meaning. These activities and events mirror what indigenous students identify with outside of school and they help students see a connection between their lives and their schooling.

One of the most important things in a bilingual education program that promotes a bicultural atmosphere is to never give precedence to any one of the cultures - even if one is more populous than the other. The detrimental effects that may go unheard when one culture is given more importance than the other are severe. For example, in one bilingual education program from Schwieter's (submitted) study publicly displayed two flags belonging to both the majority and minority cultures. However, one flag was placed over the other instead of being placed at the same level. This angered the minority students who wondered why they were participating in a bilingual/bicultural program if one culture was "place higher" than the other. Indeed, the word "bi" implies "two" and should not lead to a hierarchy where one culture enjoys being on top of the other. It sounds obvious to say that an intricate part of bilingual education involving indigenous students is to provide culturally relevant materials in a bicultural manner. However, every effort should be made to ensure that both cultures are incorporated and given importance within the school so that students can connect their life experiences to their learning experiences.

\section{CONCLUSION}

\section{Implications For Teachers And Teacher Training}

Clearly, one of the most important issues in being conscious of indigenous students' needs is teacher training that better prepares educators to come to an understanding of the language and culture of their indigenous students. Schwieter's (2002) study suggested that students were able to share a linguistic and cultural bond more so with their teachers when they were available (and able) to help them in their native language. They felt that they were better integrated, more welcomed, and cared for when teachers mentioned and incorporated activities that represented their native language and culture. For Mayan students, this could be as simple as playing counting games to learn math in the regional indigenous language to more complex teachings such as a unit on how the Mayan calendar functions. These activities with indigenous cultural foci engage Mayan students more in their learning and may lead to an increase in their desire to continue studying beyond the third grade.

In addition, it may be beneficial to incorporate real life teachings that will directly impact how Mayan students in particular will be successful members of their community. For example, a teacher may want to discuss the importance of corn in Mayan culture by doing activities that demonstrate the origin and usefulness of corn. It is likely that Mayan students are already learning such things from their parents; however, this is yet another way for teachers to bring to light what Mayan children do and learn at home with what they are being taught in school. This connection between academia and Mayan life is an essential link that must be made in order to truly have a culturally relevant curriculum.

Being conscious of indigenous students' needs first and foremost requires some understanding of and training in their traditions, values, language, and culture. Essentially, when trying to facilitate the quality of education and the positive student outcomes for indigenous students, a multilingual/multicultural instructional 
model must be considered. Figure 1 shows a visual procedure through which teachers learn to teach and subsequently teach students to learn. While maintaining a multilingual and multicultural focus, teachers could learn more about how to be linguistically and culturally sensitive to indigenous students. During this "learning to teach" time, teachers could take part in workshops and other activities that foster indigenous student learning. In the classroom, students could apply what they learn and also give a real-life implication for the indigenous students so that they can make a connection with how school relates to them personally. Only through this rich knowledge can teachers maximize learning among indigenous students and engage them in their own learning. This will allow the students to connect their traditions and home life to what they learn in the classroom and without a doubt will increase their interest in and regard for education.

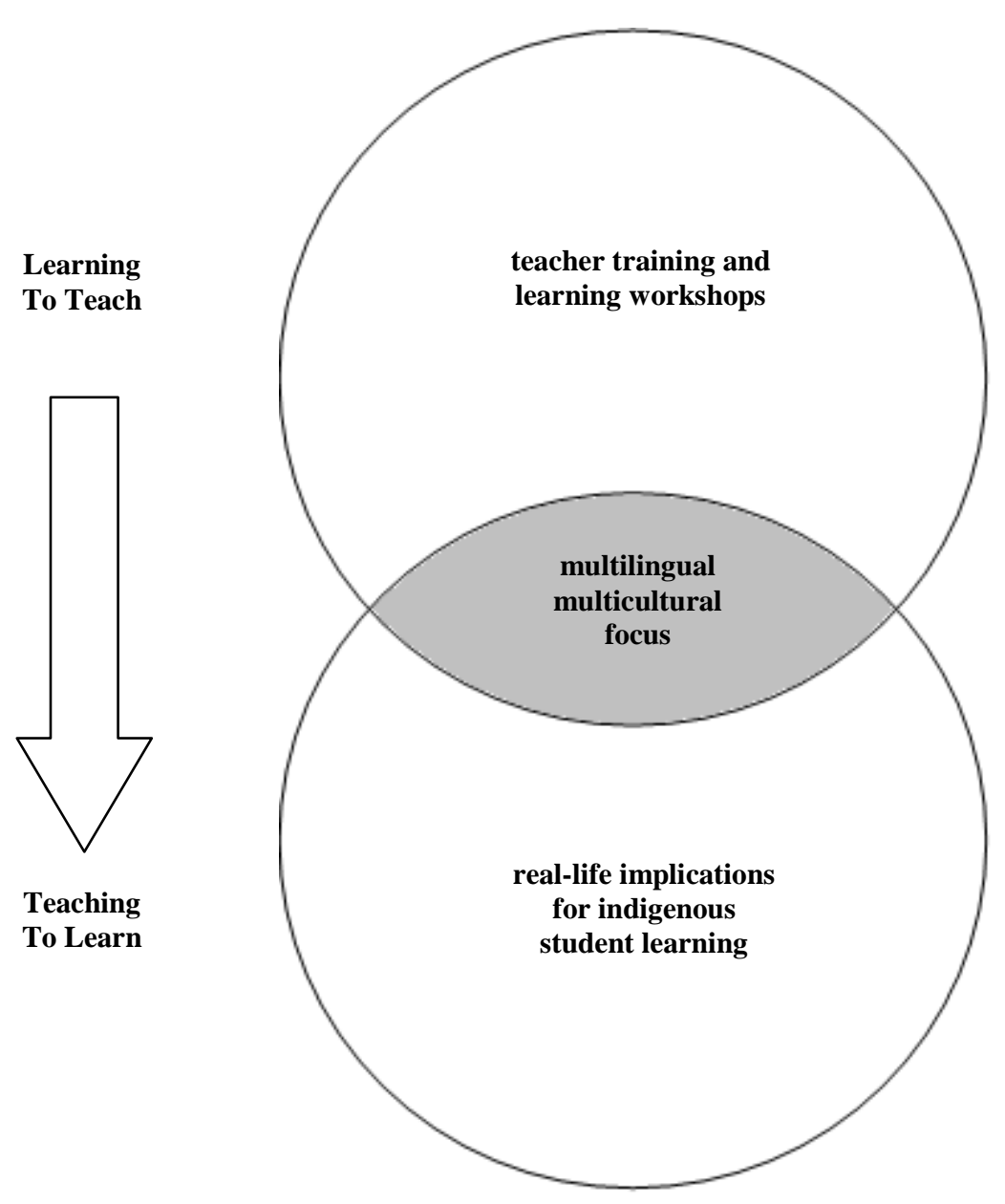

Figure 1: Teaching methodology centerea arouna muın!nguansm/muıtcuıturansm.

In this paper we have outlined how indigenous students form part of the education system. In particular, we focused on Mayans in Guatemala, not only because of their large population in the country, but also because they face many hardships that jeopardize their ability to persevere in school. We have also discussed how Mayan language, culture, and ideologies form their children into students. Given this, a number of implications for teachers of indigenous students were highlighted that can increase the extent to which teachers are conscious of indigenous students' needs in the classroom. Much more research and educational projects are merited regarding this pressing issue that will allow indigenous students to flourish and become more successful in school. 


\section{AUTHOR INFORMATION}

Dr. John W. Schwieter is an applied linguist and an assistant professor of Spanish and linguistics at Wilfrid Laurier University in Waterloo, Ontario. Dr. Schwieter's research focuses on the cognitive processes involved in speech production during language acquisition. He also conducts qualitative studies regarding Hispanic and indigenous students in ESL and mainstream classes. Dr. Schwieter has earned awards for outstanding academics, research, and teaching.

Mr. J. Luis Jaimes-Domínguez is an instructor of Spanish at Wilfrid Laurier University in Waterloo, Ontario. Mr. Jaimes is interested in Latin American literature. In particular, he has research interests in testimonial literary works focusing on limited opportunities in education and other violations of human rights.

\section{REFERENCES}

1. Anderson, M. E. (2003). Overview of the education sector. In Guatemala: Equity and Student Achievement in Primary Education (vol. 2: Background Papers). Washington, D.C.: The World Bank.

2. Delany-Barmann, G. \& Schwieter, J. W. (2004). Guatemala: An intercultural perspective. Democracy and Education, 15(1), 18-20.

3. Derwing, T. M., DeCorby, E., Ichikawa, J. (1999). Some factors that affect the success of ESL high school students. Canadian Modern Language Review, 55(4), 532-547.

4. Embassy of Guatemala. (2007). Retrieved September 5, 2007, from http://www.guatemala-embasy.org.

5. Encuesta Nacional Sobre Condiciones de Vida (ENCOVI) (2000).

6. Foley, D. E. (1991). Reconsidering anthropological explanations of ethnic school failure. Anthropology \& Education Quarterly, 22(1), 60-86.

7. Hall, G. and Patrinos, H.A. (Eds.). (2006). Indigenous Peoples, Poverty and Human Development in Latin America. London: Palgrave Macmillan.

8. Hernández-Zavala, M., Patrinos, H. A., Sakellarious, C., \& Shapiro, J. (2006). Quality of schooling and quality of schools for indigenous students in Guatemala, Mexico, and Peru. Policy Research Working Paper Series, 3982. Washington, D.C.: The World Bank.

9. Hornberger, N. (2000). Bilingual education policy and practices in the Andes: Ideological paradox and intercultural possibility. Anthropology and Education Quarterly, 31(2), 173-201.

10. McEwan, P. J. \& Trowbridge, M. (2007). The achievement of indigenous students in Guatemalan primary schools. International Journal of Educational Development, 27, 61-76.

11. Patrinos, H. A. \& Velez, E. (1996). Costs and benefits of bilingual education in Guatemala: A partial analysis. Human Capital Development Working Paper, 74. Washington, D.C.: World Bank.

12. Richards, J. B., \& Richards, M. (1997). Mayan language literacy in Guatemala: A socio historical overview. In N. Hornberger (Ed.), Indigenous Literacies in the Americas. New York: Mouton de Gruyter.

13. Rubio, F. E. (2004). Educación bilingüe en Guatemala: Situación y desafíos. Unpublished manuscript.

14. Schwieter, J. W. (2002). Hispanic students in mainstream classes: Explanations of schooling and academics (Master's thesis, Western Illinois University, 2002). Dissertation abstracts International, AAT 1427441.

15. Schwieter, J. W. (submitted). Students of a minority linguistic and cultural background speak up: Perspectives from migrant English language learners. Manuscript submitted for publication. 
NOTES 